\title{
Short communication: Inhibition of angiotensin 1-converting enzyme by peptides derived from variants of bovine $\beta$-casein upon apical exposure to a Caco-2 cell monolayer
}

\author{
Bjørn Petrat-Melin, Thao T. Le, Hanne S. Møller, Lotte B. Larsen, and Jette F. Young ${ }^{1}$ \\ Department of Food Science, Aarhus University, 8830 Tjele, Denmark
}

\begin{abstract}
This study investigated the consequence of genetically contingent amino acid substitutions in bovine $\beta$-casein $(\mathrm{CN})$ genetic variants $\mathrm{A}^{1}, \mathrm{~A}^{2}, \mathrm{~B}$, and I on the structure and bioactive potential of peptides following in vitro digestion. The $\beta$-CN variants were digested in vitro using pepsin and pancreatin, and a peptide profile was obtained by liquid chromatography tandem mass spectrometry, revealing among others, the $\beta$-casomorphin precursor peptides VYPFPGPIHN and VYPFPGPIPN, derived from variant $\mathrm{A}^{1} / \mathrm{B}$ and from $\mathrm{A}^{2} / \mathrm{I}$, respectively. These 2 peptides were synthesized and assessed for angiotensin 1-converting enzyme (ACE) inhibitory capacity before and after incubation with a monolayer of Caco-2 intestinal cells. The VYPFPGPIHN was a stronger ACE inhibitor than VYPFPGPIPN, with the concentration needed to reach half-maximal inhibition $\left(\mathrm{IC}_{50}\right)$ of 123 $\pm 14.2 \mu M$ versus $656 \pm 7.6 \mu M$. Exposure to a Caco-2 intestinal cell monolayer did not affect ACE inhibition by VYPFPGPIHN, but resulted in an almost 2-fold increase in inhibition by VYPFPGPIPN after incubation. Subsequent tandem mass spectrometric analysis identified the truncated peptide VYPFPGPIP, suggesting hydrolysis by a cell membrane associated peptidase. Thus, genetic variation in bovine $\beta-\mathrm{CN}$ results in the generation of peptides that differ in bioactivity, and are differently affected by intestinal brush border peptidases.
\end{abstract}

Key words: angiotensin 1-converting enzyme, betacasein, bioactive peptide, genetic variant, in vitro digestion

\section{Short Communication}

Bioactive peptides are protein fragments that are encrypted within the sequence of a parent protein, and can be liberated by the action of proteolytic enzymes

Received June 30, 2016.

Accepted October 30, 2016.

${ }^{1}$ Corresponding author: jettef.young@food.au.dk (e.g., in the controlled processing of raw materials) or in the gastrointestinal tract (Phelan et al., 2009). Approximately one-third of the protein in bovine milk is $\beta-\mathrm{CN}$, and so far 15 genetic variants carrying amino acid substitutions have been described (Caroli et al., 2009; Gallinat et al., 2013), exemplified in a substantial variation in milk from Danish dairy cows (N. A. Poulsen, H. B. Jensen, H. S. Møller, M. Hammershøj, and L. B. Larsen, Department of Food Science, Aarhus University, unpublished data). Bovine $\beta-\mathrm{CN}$ has been shown to be an outstanding source of bioactive peptides that may exert physiologically beneficial effects, such as immune modulation, mineral binding, opioid agonism, thrombin inhibition, antioxidant capacity, and reduction of blood pressure through angiotensin 1-converting enzyme (ACE) inhibition (Meisel, 1998; Korhonen and Pihlanto, 2006). The World Health Organisation assessed the global prevalence of hypertension to be approximately $40 \%$ for adults 25 yr or older (WHO, 2009), and it is estimated to cause close to 10 million deaths annually (Lim et al., 2012). This has led to much research into ACE inhibitory effects of foodderived peptides during recent decades, and a large number of milk-derived ACE inhibitory peptides have been identified, including many from $\beta$-CN (FitzGerald et al., 2004). The inhibitory capacity of a peptide is determined by its sequence, and the amino acid residues at the C-terminal in particular. Cheung et al. (1980) published the results of one of the first systematic investigations into this particular subject more than 3 decades ago. Since then, many studies have followed, showing that ACE inhibitory peptides can possess quite diverse structural characteristics. Most of these peptides have been cataloged in online databases, such as Biopep (Minkiewicz et al., 2008) and ACEpepDB (http://www.cftri.com/pepdb/index.php). From this, it follows that modifications to the amino acid sequence of proteins could affect their potential for generation of ACE inhibitory peptides. Such modifications can be the result of genetic polymorphisms manifested in amino acid substitutions, which have been shown to be of consequence for the digestion pattern of $\beta$-CN 
variants (Lisson et al., 2013; Petrat-Melin et al., 2015). This issue has been the matter of extensive scientific debate as genetic polymorphism in $\beta-\mathrm{CN}$ has been suggested to underlie the pathogenesis of noncommunicable diseases, such as type-1 diabetes, autism, and cardiovascular disease (Bell et al., 2006; Kaminski et al., 2007). Nevertheless, no clear causal relationship has been established, and mechanistic evidence is still lacking (Noni et al., 2009). This issue is beyond the scope of the present work and will thus not be discussed further.

Besides peptide sequence variation, it is also essential to consider the stability of any bioactive peptides when exposed to the intestinal environment. Both animal and human intervention studies with different allegedly anti-hypertensive foods, hydrolysates, or peptides have been reported (FitzGerald et al., 2004; Fekete et al., 2013; Iwaniak et al., 2014). Some of these provide evidence for the survival and intestinal uptake of ACE inhibitory peptides, and even systemic blood pressure lowering effects.

The aim of the present work was to investigate the effect of genetic variation in $\beta-\mathrm{CN}$ on the peptides generated by in vitro gastrointestinal digestion (IVD) of $\beta$-CN variants $\mathrm{A}^{1}, \mathrm{~A}^{2}, \mathrm{~B}$, and I (Table 1 ). Two peptides, related to previously described bioactive peptides (Saito et al., 2000; Eisele et al., 2013), derived from different variants of $\beta-\mathrm{CN}$, were synthesized and assessed for ACE inhibition. Furthermore, the effect of ACE inhibition upon exposure to the human Caco-2 intestinal cell line was investigated.

$\beta$-Casein genetic variants $\mathrm{A}^{1}, \mathrm{~A}^{2}, \mathrm{~B}$, and I were isolated from milk samples obtained from homozygous cows of known $\beta$-CN genotype (Poulsen et al., 2013) and were subjected to IVD using pepsin and pancreatin in 2 consecutive steps, as previously described (PetratMelin et al., 2015). A peptide profile of the resulting hydrolysates was obtained by liquid chromatography tandem mass spectrometry (LC-MS/MS). The LC system consisted of a 1200 series capillary pump and autosampler (Agilent Technologies, Waldbronn, Germany) fitted with a Jupiter C18 300 A micro-column (Phenomenex, Værløse, Denmark) of dimensions 150 $\mathrm{mm} \times 0.5 \mathrm{~mm}$ with a particle size of $5 \mu \mathrm{m}$. The gradient of solvent A (1\% acetic acid) and solvent B $(80 \%$ acetonitrile, $1 \%$ acetic acid) was as follows: $2 \%$ B over 5 min increasing to $100 \%$ B over 25 min, and keeping at $100 \% \mathrm{~B}$ for $10 \mathrm{~min}$ at a flow rate of $10 \mu \mathrm{L} / \mathrm{min}$. The column was operated at $20^{\circ} \mathrm{C}$. The LC system was coupled to an HCT Ultra ion-trap tandem mass spectrometer equipped with an electrospray ion source (Bruker Daltonik, Bremen, Germany). The MS was run in positive mode with an $m / z$ range from 250 to 2,000 . Tandem MS spectra were recorded and searched against a custom Mascot database (Matrix Science, Boston, MA) of bovine milk proteins, including genetic variants. The search was performed with no specific enzyme cleavage sites, an MS mass tolerance of $0.1 \%$, and an MS/ MS mass tolerance of 0.5 Da. Peptide hits above the Mascot score significance threshold $(P<0.05)$ were accepted. Fourteen unique peptides from the regions of amino acid substitutions were positively identified (not shown). In the digest from all $4 \beta$-CN variants, the V-betacasomorphin-9 (V-ßCM-9) like decapeptide $\beta-\mathrm{CN}$ f59-68 was found, constituting VYPFPGPIHN from variants $\mathrm{A}^{1}$ and $\mathrm{B}$, and VYPFPGPIPN from variants $\mathrm{A}^{2}$ and I. Boutrou et al. (2013) identified also this peptide and 4 additional $\beta \mathrm{CM}$ precursors from jejunal aspirates of healthy human subjects. However, being aspirated from the lumen of the intestine, these peptides will likely not have been in proximity of brush border peptidases (BBP). Peptide VYPFPGPIPN has previously been observed in a system where $\mathrm{CN}$ was hydrolysed with Bacillus lentus alkaline peptidase, and was found to be an ACE inhibitor with an concentration needed to reach half-maximal inhibition $\left(\mathbf{I C}_{\mathbf{5 0}}\right)$ of $325 \mu M$ (Eisele et al., 2013). Moreover, $\mathrm{A}^{2} / \mathrm{I}$ derived $\beta C M-9$ (i.e., YPFPGPIPN), was shown to be a much stronger ACE inhibitor with an $\mathrm{IC}_{50}$ of $14.8 \mu M$ (Saito et al., 2000). However, the $\mathrm{ACE}$ inhibition of $\mathrm{A}^{1} / \mathrm{B}$ derived V-BCM-9 has not previously been reported. Therefore, to explore the consequence of genetic polymorphism for ACE inhibitory capacity the 2 V- $\beta$ CM-9 peptides were synthesized by Schafer-N (Copenhagen, Denmark) using solid phase synthesis. Angiotensin 1-converting enzyme inhibition was determined using a modified version of the method of Sentandreu and Toldra (2006) as previously described (Petrat-Melin et al., 2015). The peptides were measured at 7 different concentrations, and the $\mathrm{IC}_{50}$ values were determined by 4 parameter logistic regression using SigmaPlot version 11 (Systat Software, Erkrath, Germany; Table 2). The $\mathrm{A}^{1} / \mathrm{B}$ derived $\mathrm{V}-\beta \mathrm{CM}-9$ was a rather potent $\mathrm{ACE}$ inhibitor, with an $\mathrm{IC}_{50}$ more than 5-fold lower than the $\mathrm{A}^{2} / \mathrm{I}$ derived $\mathrm{V}-\beta \mathrm{CM}-9$, suggesting that the H67P substitution in the $\mathrm{A}^{2}$ and I variants is unfavorable for ACE inhibition. This is in accordance with $\mathrm{Wu}$ et al. (2006) who found $\mathrm{H}$ to be one of the more favorable

Table 1. Position of amino acid substitutions ${ }^{1}$ within the mature protein of variants of $\beta-\mathrm{CN}$

\begin{tabular}{lllll}
\hline & \multicolumn{4}{c}{ Variant $^{1}$} \\
\cline { 2 - 5 } Position & $\mathrm{A}^{1}$ & $\mathrm{~A}^{2}$ & $\mathrm{~B}$ & $\mathrm{I}$ \\
\hline 67 & His (H) & Pro (P) & & Pro (P) \\
93 & Met (M) & & Arg (R) & \\
122 & Ser (S) & & Arg \\
\hline
\end{tabular}

${ }^{1} \mathrm{~A}^{1}$ is the reference sequence (Caroli et al., 2009). 
residues to have at the penultimate position of peptides of 4 to $10 \mathrm{AA}$ in length, concerning $\mathrm{ACE}$ inhibition.

The final phase of protein and peptide digestion takes place in the small intestine immediately before the resulting peptides and $\mathrm{AA}$ are transported across the intestinal wall. To exert any physiological effect, ACE inhibitory peptides must resist further degradation by the brush border enzymes of the enterocytes. This was evaluated in the present study by exposure to the human intestinal cell line Caco-2, obtained from the American Type Culture Collection (HTB-37, ATCC, Manassas, VA). The cells were propagated using standard cell culture techniques. In brief, they were cultured in complete growth medium (GM, Dulbecco's modified Eagle's medium supplemented with $10 \%$ fetal bovine serum, $100 \mathrm{U} / \mathrm{mL}$ penicillin, $0.1 \mathrm{mg} / \mathrm{mL}$ streptomycin, $1 \%$ NEAA) in $75-\mathrm{cm}^{2}$ cell culture flasks at $37^{\circ} \mathrm{C}, 95 \%$ air, and $5 \% \mathrm{CO}_{2}$ in a humidified incubator. TrypsinEDTA, Dulbecco's modified Eagle medium, and fetal bovine serum were from Gibco (Naerum, Denmark). Penicillin/streptomycin, Hanks' buffered salt solution (HBSS), HEPES, 2-( $N$-morpholino)ethanesulfonic acid, lucifer yellow, and NEAA were all from Sigma Aldrich (St. Louis, MO). Growth medium was changed 3 times weekly. Subculturing was performed at 50 to $60 \%$ confluency by washing twice with PBS, and incubating with $1.25 \mathrm{mg} / \mathrm{mL}$ of trypsin and $0.1 \mathrm{mg} / \mathrm{mL}$ of EDTA for 5 to $10 \mathrm{~min}$ until detachment was observed. The cell suspension was centrifuged at $200 \times g$ for 4 min at room temperature. The supernatant was discarded and the cells were resuspended in fresh GM for re-seeding. For the assay, the Caco- 2 cells were seeded at a density of $6.5 \times 10^{4}$ cells $/ \mathrm{cm}^{2}$ on polycarbonate cell culture inserts with a pore size of $0.4 \mu \mathrm{m}$ and a growth surface area of $0.6 \mathrm{~cm}^{2}$ (Merck-Millipore, Darmstadt, Germany) and kept in standard 24-well cell culture plates. They were allowed to proliferate and differentiate into a tight monolayer for 20 to $25 \mathrm{~d}$, with GM changed 3 times weekly. The integrity of the monolayers was assessed by measuring the trans-epithelial electrical resistance (TEER) with an ERS-2 Volt-ohm meter equipped with chopstick electrodes (Merck-Millipore). The TEER values were calculated as $\left(\Omega_{\text {monolayer }}-\Omega_{\text {blank }}\right)$ $\times 0.6 \mathrm{~cm}^{2}$, and only inserts with values above $200 \Omega$ $\times \mathrm{cm}^{2}$, measured at $37^{\circ} \mathrm{C}$, were used for experiments. The V- $\beta$ CM-9 were assessed for retention of inhibitory capacity after incubation with the Caco-2 cell monolayer, as described in the following. First, the inserts were washed in HEPES-buffered HBSS (pH 7.4) at $37^{\circ} \mathrm{C}$ for $10 \mathrm{~min}$ while measuring initial TEER values. Then, the inserts were incubated with samples dissolved in 2-( $N$-morpholino)ethanesulfonic acid-buffered HBSS ( $\mathrm{pH}$ 6.5) in the apical chamber, and with fresh HEPES-buffered HBSS in the basolateral chamber. The initial concentration of the peptides was $500 \mu \mathrm{M}$. Lucifer yellow was added at $100 \mu M$ to all samples and controls for assessment of monolayer integrity during the assay. The incubation was carried out at $37^{\circ} \mathrm{C}$ for $120 \mathrm{~min}$ on a rocker table set to $30 \mathrm{rpm}$, and TEER values were measured again at the end of incubation. Only data from inserts where less than $1 \%$ of the initial lucifer yellow had leaked into the basolateral chamber, and the loss in TEER value was less than $25 \%$, were used. Experimental solutions from both apical and basolateral chambers were aspirated at the end of incubation, and kept at $-20^{\circ} \mathrm{C}$ until further analysis. The observed changes in inhibition measured in the apical samples were significantly different between the 2 peptides $(P<0.001)$, with no change for VYPFPGPIHN $(P>0.05)$, and an $81 \%$ increase for VYPFPGPIPN $(P<0.05$; Figure 1$)$. Interestingly, in addition to the intact peptides, the C-terminally truncated VYPFPGPIH and VYPFPGPIP were detected in the apical chamber following incubation. This likely resulted in a more favorable $\mathrm{C}$-terminal for the $\mathrm{A}^{2}$ derived peptide (-PIP) than for the $\mathrm{A}^{1}$ derived $(-\mathrm{PIH})$. In addition, no significant uptake or transport of these 2 peptides was noted, evidenced by no appearance of activity in the basolateral chamber, and no peptides detected by LC-MS/MS. Nevertheless, it was earlier shown that the hexapeptide LHLPLP [ $\beta$-CN f(133-138)] was both transported and converted into HLPLP by Caco- 2 cells (Quirós et al., 2008). Transport of $\beta$ CM-7 (YPFPGPI) across a Caco-2 monolayer has also been demonstrated, but this peptide was also extensively hydrolyzed by dipeptidyl peptidase IV (DPP-IV; Iwan et al., 2008). The DPP-IV hydrolyzes $\beta$ CM-7 because it favors peptide substrates with a $\mathrm{P}$ residue in the second position

Table 2. The $\mathrm{IC}_{50}{ }^{1}$ of angiotensin 1-converting enzyme inhibitory peptides derived from $\beta$-CN variants

\begin{tabular}{|c|c|c|c|c|}
\hline Peptide & Variant & Position $^{2}$ & $\mathrm{IC}_{50}(\mu M)$ & SEM \\
\hline VYPFPGPIHN & $\mathrm{A}^{1}, \mathrm{~B}$ & 59-68 & $123^{\mathrm{a}}$ & 14.2 \\
\hline VYPFPGPIPN & $\mathrm{A}^{2}, \mathrm{I}$ & $59-68$ & $656^{\mathrm{b}}$ & 7.6 \\
\hline
\end{tabular}




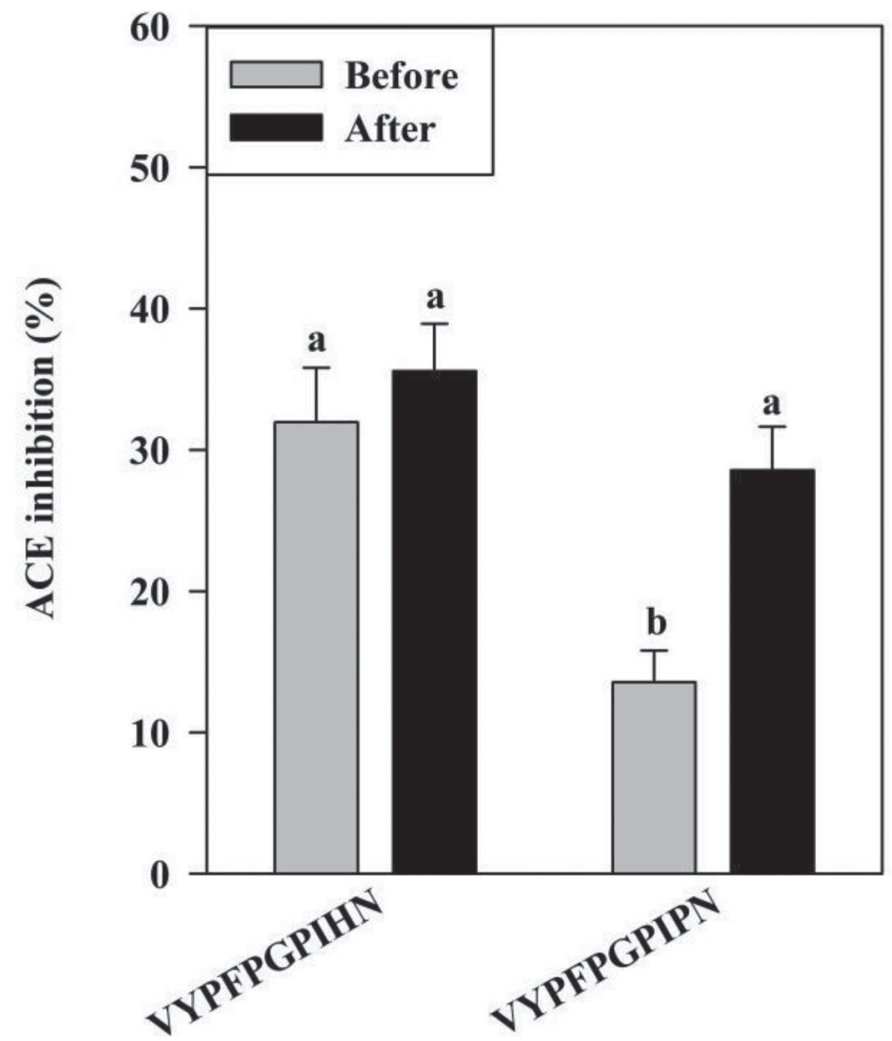

Figure 1. Angiotensin 1-converting enzyme (ACE) inhibition by $\beta$-CN-derived peptides, measured at $83 \mu \mathrm{M}$, before and after $120 \mathrm{~min}$ incubation with the apical side of a differentiated Caco-2 cell monolayer. Different letters indicate a significant difference $(P<0.01)$ in ACE inhibition before and after incubation. Error bars represent SEM $(\mathrm{n}=3)$.

from the N-terminal, from which it cleaves a dipeptide (Chen, 2006). The added V residue at the N-terminal of V- $\beta$ CM-9 likely prevents the action of DPP-IV. In another study of milk protein digestion, using an in vitro system that included $\mathrm{BBP}$, only $2 \beta \mathrm{CM}$ were identified [ $\beta$-CN $\mathrm{f}(60-66)$ and $\mathrm{f}(60-67)]$ (Picariello et al., 2015). Compared with the work of Boutrou et al. (2013), this highlights the role of BBP in the degradation of ingested proteins before absorption. However, further studies should elucidate whether there is any matrix effect on intestinal digestion by luminal peptidases as well as BBP, and on subsequent absorption, when digesting complete milk samples.

In summary, the present study shows that genetic polymorphisms result in different peptides being generated during IVD of $\beta-C N$ variants $A^{1}, A^{2}, B$, and $I$. As a result, peptides with varying ACE inhibitory capacities were observed. In addition, contrasting effects of proteolysis by intestinal cell associated proteases was shown. However, no apparent transport of ACE inhibitory peptides across the Caco-2 monolayer was observed. Taken together, this demonstrates that protein variation at the sequence level may influence both gastrointestinal digestion and the bioactive potential of generated peptides.

\section{ACKNOWLEDGMENTS}

The Danish sampling and analysis team from the Danish-Swedish Milk Genomics Initiative are gratefully acknowledged for excellent technical assistance. Moreover, Bjørn Petrat-Melin is grateful to the Graduate School of Science and Technology at Aarhus University for the individual $\mathrm{PhD}$ scholarship that made the presented work possible. The authors declare no conflict of interest.

\section{REFERENCES}

Bell, S. J., G. T. Grochoski, and A. J. Clarke. 2006. Health Implications of Milk Containing Beta-Casein with the A2 Genetic Variant. Pages 93-100 in Crit. Rev. Food Sci. Nutr. Vol. 46. Taylor \& Francis.

Boutrou, R., C. Gaudichon, D. Dupont, J. Jardin, G. Airinei, A Marsset-Baglieri, R. Benamouzig, D. Tomé, and J. Leonil. 2013. Sequential release of milk protein-derived bioactive peptides in the jejunum in healthy humans. Am. J. Clin. Nutr. 97:1314-1323.

Caroli, A. M., S. Chessa, and G. J. Erhardt. 2009. Invited review: Milk protein polymorphisms in cattle: Effect on animal breeding and human nutrition. J. Dairy Sci. 92:5335-5352.

Chen, X. 2006. Biochemical properties of recombinant prolyl dipeptidases DDP-IV and DPP8. Pages 27-32 in Dipeptidyl Aminopeptidases: Basic Science and Clinical Applications. Vol. 575. U. Lendeckel, D. Reinhold, and U. Bank, ed. Springer US, Boston, MA.

Cheung, H. S., F. L. Wang, M. A. Ondetti, E. F. Sabo, and D. W Cushman. 1980. Binding of peptide substrates and inhibitors of angiotensin-converting enzyme. Importance of the $\mathrm{COOH}$-terminal dipeptide sequence. J. Biol. Chem. 255:401-407.

Eisele, T., T. Stressler, B. Kranz, and L. Fischer. 2013. Bioactive peptides generated in an enzyme membrane reactor using Bacillus lentus alkaline peptidase. Eur. Food Res. Technol. 236:483-490.

Fekete, A. A., D. I. Givens, and J. A. Lovegrove. 2013. The impact of milk proteins and peptides on blood pressure and vascular function: A review of evidence from human intervention studies. Nutr. Res. Rev. 26:177-190.

FitzGerald, R. J., B. A. Murray, and D. J. Walsh. 2004. Hypotensive peptides from milk proteins. J. Nutr. 134:980S-988S.

Gallinat, J. L., S. Qanbari, C. Drögemüller, E. C. Pimentel, G. Thaller, and J. Tetens. 2013. DNA-based identification of novel bovine casein gene variants. J. Dairy Sci. 96:699-709.

Iwan, M., B. Jarmołowska, K. Bielikowicz, E. Kostyra, H. Kostyra and M. Kaczmarski. 2008. Transport of $\mu$-opioid receptor agonists and antagonist peptides across Caco-2 monolayer. Peptides 29:1042-1047.

Iwaniak, A., P. Minkiewicz, and M. Darewicz. 2014. Food-originating ACE inhibitors, including antihypertensive peptides, as preventive food components in blood pressure reduction. Compr. Rev. Food Sci. Food Saf. 13:114-134.

Kaminski, S., A. Cieslinska, and E. Kostyra. 2007. Polymorphism of bovine beta-casein and its potential effect on human health. J. Appl. Genet. 48:189-198.

Korhonen, H., and A. Pihlanto. 2006. Bioactive peptides: Production and functionality. Int. Dairy J. 16:945-960.

Lim, S. S., T. Vos, A. D. Flaxman, G. Danaei, K. Shibuya, and H. Adair-Rohani.. 2012. A comparative risk assessment of burden of 
disease and injury attributable to 67 risk factors and risk factor clusters in 21 regions, 1990-2010: A systematic analysis for the Global Burden of Disease Study 2010. Lancet 380:2224-2260.

Lisson, M., G. Lochnit, and G. Erhardt. 2013. Genetic variants of bovine beta- and kappa-casein result in different immunoglobulin Ebinding epitopes after in vitro gastrointestinal digestion. J. Dairy Sci. 96:5532-5543.

Meisel, H. 1998. Overview on milk protein-derived peptides. Int. Dairy J. 8:363-373

Minkiewicz, P., J. Dziuba, A. Iwaniak, M. Dziuba, and M. Darewicz. 2008. BIOPEP database and other programs for processing bioactive peptide sequences. J. AOAC Int. 91:965-980.

Noni, I. D., R. J. Fitzgerald, H. J. T. Korhonen, Y. Le Roux, C. T. Livesey, I. Thorsdottir, D. Tome, and R. Witkamp. 2009. Scientific Report of EFSA prepared by a DATEX Working Group on the potential health impact of $\beta$-casomorphins and related peptides. 1-107. European Food Safety Authority, Parma, Italy.

Petrat-Melin, B., P. Andersen, J. T. Rasmussen, N. A. Poulsen, L. B. Larsen, and J. F. Young. 2015. In vitro digestion of purified beta-casein variants $\mathrm{A}(1), \mathrm{A}(2), \mathrm{B}$, and I: Effects on antioxidant and angiotensin-converting enzyme inhibitory capacity. J. Dairy Sci. 98:15-26.

Phelan, M., A. Aherne, R. J. FitzGerald, and N. M. O'Brien. 2009 Casein-derived bioactive peptides: Biological effects, industrial uses, safety aspects and regulatory status. Int. Dairy J. 19:643-654.
Picariello, G., B. Miralles, G. Mamone, L. Sánchez-Rivera, I. Recio, F. Addeo, and P. Ferranti. 2015. Role of intestinal brush border peptidases in the simulated digestion of milk proteins. Mol. Nutr. Food Res. 59:948-956.

Poulsen, N. A., H. P. Bertelsen, H. B. Jensen, F. Gustavsson, M. Glantz, H. L. Månsson, A. Andrén, M. Paulsson, C. Bendixen, A. J. Buitenhuis, and L. B. Larsen. 2013. The occurrence of noncoagulating milk and the association of bovine milk coagulation properties with genetic variants of the caseins in 3 Scandinavian dairy breeds. J. Dairy Sci. 96:4830-4842.

Quirós, A., A. Dávalos, M. A. Lasunción, M. Ramos, and I. Recio. 2008. Bioavailability of the antihypertensive peptide LHLPLP: Transepithelial flux of HLPLP. Int. Dairy J. 18:279-286.

Saito, T., T. Nakamura, H. Kitazawa, Y. Kawai, and T. Itoh. 2000. Isolation and structural analysis of antihypertensive peptides that exist naturally in Gouda cheese. J. Dairy Sci. 83:1434-1440.

Sentandreu, M. A., and F. Toldra. 2006. A rapid, simple and sensitive fluorescence method for the assay of angiotensin-I converting enzyme. Food Chem. 97:546-554.

WHO. 2009. Global Health Observatory-Raised blood pressure. Vol. 2014. World Health Organisation, Geneva, Switzerland.

Wu, J., R. Aluko, and S. Nakai. 2006. Structural requirements of angiotensin I-converting enzyme inhibitory peptides: Quantitative structure-activity relationship modeling of peptides containing 4-10 amino acid residues. QSAR Comb. Sci. 25:873-880. 